\title{
PHYTOCHEMICAL CHARACTERIZATION AND ANTIOXIDANT ACTIVITY OF THE NORTHERN MOROCCAN SPECIES: WITHANIA FRUTESCENS L.
}

\author{
ABDELFATTAH EL MOUSSAOUI ${ }^{1 *}$, FATIMA ZAHRA JAWHARI ${ }^{1}$, DALILA BOUSTA ${ }^{2}$, AMINA BARI ${ }^{1}$ \\ ${ }^{1}$ Laboratory of Biotechnology and Preservation of Natural Resources, Faculty of Sciences, Dhar El Mahraz, Sidi Mohammed Ben Abdallah \\ University, Fez, Morocco. ${ }^{2}$ Laboratory of Neuroendocrinology and Nutritional and Climatic Environment, Faculty of Sciences Dhar El \\ Mahraz, Sidi Mohammed Ben Abdallah University, Fez, Morocco. Email: abdelfattah.elmoussaoui@usmba.ac.ma
}

Received: 23 January 2019, Revised and Accepted: 06 May 2019

ABSTRACT

Objective: In this study, we were interested in qualitative, quantitative phytochemical characterization and evaluation of the antioxidant capacity of the total extracts of a plant from northern Morocco, the species selected for this study is Withania frutescens.

Materials and Methods: Analysis of mineral elements by inductive coupling plasma-atomic absorption spectroscopy (ICP-AES), phytochemical screening, polyphenol and tannin assays, evaluation of antioxidant activity by the 1,2-diphenyl- $\beta$-picrylhydrazyl (DPPH) free radical scavenging method and reducing power.

Results: The plant contains alkaloids, saponins, tannins, mucilages, and coumarins. It has a relatively high content of total polyphenols and tannins of $19.53 \pm 0.018 \mu \mathrm{g}$ genetic generalized epilepsy/mg MS and $6.258 \pm 0.062 \mu \mathrm{g}$ Eqcat/mg MS, respectively. The analysis of mineral elements by ICP-AES shows that our species is rich in mineral elements which are calcium, magnesium, and sodium, and it is devoid of metallic elements such as nickel, lead, cadmium, and cobalt. The evaluation of antioxidant activity by the DPPH free radical scavenging method shows that the half maximal inhibitory concentration of the tested extracts has an antiradical activity of about $0.056 \pm 0.008 \mu \mathrm{g} / \mathrm{ml}$ for the ethanol extract and $0.213 \pm 0.004 \mu \mathrm{g} / \mathrm{ml}$ for the methanol extract compared to the butylated hydroxytoluene value of $0.009 \pm 0.0004 \mu \mathrm{g} / \mathrm{ml}$ which was used as a reference. The reducing capacity test shows that methanolic extract has a high antioxidant capacity $(0.213 \pm 0.006)$ compared to ethanolic extract $(0.043 \pm 0.004)$ but remains low compared to ascorbic acid $(0.003 \pm 0.0004)$ which was used as reference.

Conclusion: Phytochemical analysis of $W$. frutescens shows that this plant is rich in high quantities of alkaloids, saponins, mucilage, tannins, and coumarins. It contains an average amount of total polyphenols and tannins that confer significant antioxidant activity to the plant studied.

Keywords: Phytochemical screening, Inductive coupling plasma-atomic absorption spectroscopy analysis, 1,2-diphenyl- $\beta$-picrylhydrazyl, Reducing power. (C) 2019 The Authors. Published by Innovare Academic Sciences Pvt Ltd. This is an open access article under the CC BY license (http://creativecommons. org/licenses/by/4. 0/) DOI: http://dx.doi.org/10.22159/ajpcr.2019.v12i6.32119

\section{INTRODUCTION}

The use of natural herbal molecules instead of synthetic drugs has proven to be more effective and with fewer side effects. However, they can be fatal or toxic to the body if they are used unreasonably. Phytochemical techniques make it possible to extract active substances present in the various parts of the plants by means of solvents with different polarities to obtain a maximum yield. All these techniques consist initially of a purification of the compounds sought to isolate the active substances that can be used in the design of phytomedicaments [1]. In the context of preliminary studies in research on active substances in medicinal plants, we chose Withania frutescens, a natural species in Morocco known for its use in the treatment of poisoning in traditional pharmacopoeia [2]. It is also a honey plant due to its inflorescence rich in nectar. It has been shown the possibility of using this plant in wastewater treatment for the removal of mineral metal ions [3]; furthermore, some studies showed that this plant contains high concentrations of alkaloids, saponins, catechic tannins, and flavonoids [4]. In this perspective, our study aims to carry out a qualitative and quantitative photochemical characterization of the total extracts of this species to identify the active substances that can be used in the production of phytomedicaments.

\section{MATERIALS AND METHODS}

\section{Preparation of the crude extract}

The plant material used in this work includes the aerial parts of $W$. frutescens L. The leaves and flowering stems were collected from a shrub. For the sampling period, spring extends from March to April 2017 because it is the season when development and flowering are at their peak. After harvesting, we cleaned the plant material by washing it in water to ensure proper conservation of the plant. It was dried at $35^{\circ} \mathrm{C}$, stored in a sheltered place for a few days before being crushed by a mixer and stored in boxes. Hydroalcoholic extracts were prepared by the method of maceration of vegetable powder at room temperature using $70 \%$ methanol and ethanol separately at a rate of $1 / 10(\mathrm{~W} / \mathrm{V})$ for $24 \mathrm{~h}$. The third extract has been realized by a decoction for $30 \mathrm{~min}$ then filtered using Whatman filter paper.

\section{Ash content determination}

The ash content has been evaluated according to the French standard NF V05-113 [5]. $5 \mathrm{~g}$ of the vegetable powder was weighed in porcelain capsules and then placed in a muffle oven at $550 \pm 15{ }^{\circ} \mathrm{C}$ for $5 \mathrm{~h}$ until a grey, light, or whitish color was obtained. The ash content was calculated using the following expression:

$$
\mathrm{OM} \%=[(\mathrm{M} 1-\mathrm{M} 1) / \mathrm{P}] \times 100
$$

$\mathrm{Cd}=100-0 \mathrm{M} \%$

Where, OM\%: Organic matter, M1: Mass of the capsules+test sample, M2: Mass of the capsules+ashes, P: Mass of the test sample.

Determination of mineral element content by atomic absorption spectroscopy (AES)

About $1 \mathrm{~g}$ of the incinerated vegetable powder of the species studied is added to $1 \mathrm{ml}$ of hydrochloric acid and $10 \mathrm{ml}$ of distilled water. After heating the mixture in a water bath until the ash dissolved, the 
volume was filled to $100 \mathrm{ml}$ with distilled water. From this solution, the following mineral elements were determined by AES with inductive coupling plasma (ICP-AES): Sodium, lead, copper, magnesium, cobalt, cadmium, nickel, molybdate, calcium, and manganese.

\section{Phytochemical screening}

The screening is considered ASA preliminary stage, for this reason, we have carried out a phytochemical screening for the purpose of determining the phytochemical families of the selected plant. We highlighted the following metabolites: Flavonoids, tannins, terpenes, coumarins, cyanogenic compounds, alkaloids, quinones, and saponins [6].

Determination of total polyphenol and condensed tannin contents The quantification of total phenolic compounds was performed using Singleton's method [7] with the Folin-Ciocalteu (F-C) reagent. $500 \mu \mathrm{l}$ of diluted F-C reagent $(1 / 10)$ is added to $100 \mu$ l of methanolic extract. After a few minutes, $400 \mu \mathrm{l}$ of a sodium carbonate solution $(75 \mathrm{mg} / \mathrm{ml})$ are added to the reaction medium. After incubation in the dark and at room temperature for $2 \mathrm{~h}$, the absorbance is measured at $765 \mathrm{~nm}$. The results obtained are expressed in $\mu$ g gallic acid equivalent per milligram of dry extract ( $\mu \mathrm{g} \mathrm{Eq} \mathrm{A.G/mg} \mathrm{extract)} \mathrm{using} \mathrm{the} \mathrm{linear} \mathrm{regression}$ equation of the gallic acid calibration curve.

The tannin content in the deferent extracts from the plant studied was determined using vanillin method in acid medium [8]: The vanillin reagent was prepared by mixing the following dilutions at equal volume: $\mathrm{HCl}$ at $8 \%(\mathrm{v} / \mathrm{v})$, methanol at $37 \%(\mathrm{v} / \mathrm{v})$, and $4 \%$ vanillin in methanol $(\mathrm{m} / \mathrm{v})$. The mixture was incubated at $30^{\circ} \mathrm{C}$ in a few minutes before dosing. On $200 \mu \mathrm{l}$ of each test, extract was added to $1 \mathrm{ml}$ of vanillin reagent and incubated in the dark at $30^{\circ} \mathrm{C}$ for $20 \mathrm{~min}$. The absorbance is measured at $500 \mathrm{~nm}$ by a spectrophotometer against a blank consisting of a mixture of the same volume of methanol (37\%) and $\mathrm{HCl}(8 \%)$. The results are expressed in $\mu \mathrm{g}$ catechol equivalent/mg of dry extract with reference to the catechol calibration curve.

1,2-diphenyl-1-picrylhydrazyle (DPPH) radical scavenging activity The DPPH radical scavenging activity test was performed using Brand's method [9] with a small modification. In brief, $800 \mu \mathrm{l}$ volume of $0.1 \mathrm{mM}$ ethanolic solution of DPPH solution was added to $200 \mu \mathrm{l}$ of a dilution series of plant extracts ranging from 1.36 to $50 \mathrm{mg} / \mathrm{ml}$, then incubated in the dark for $1 \mathrm{~h}$.

Absorbance was estimated in $1 \mathrm{ml}$ cuvettes at $517 \mathrm{~nm}$ using a Perkin Elmer Lambda 40 ultraviolet-visible (UV/VIS) spectrophotometer against ethanol the control where DPPH and extract were absent. The experiment was performed in triplicates and the average absorption was noted for each concentration. Butylated hydroxytoluene (BHT) was used as the standard solution. The percentages of inhibition of the DPPH radical by the samples were calculated according to the following formula:

The absorbance of the negative control-The absorbance of the sample The negative control absorbance

The standard graph was plotted against the sample concentration, with the X-axis representing the concentration of BHT as a positive control and the percentage of scanning activity on the coordinate axis.

\section{Determination of the reducing power}

This test was performed according to the method described by Oyaizu [10] with slight modifications. A volume of $150 \mu$ l extract was added to $200 \mu \mathrm{l}$ potassium buffer $0.2 \mathrm{M}(\mathrm{pH} 6.6)$ and $200 \mu \mathrm{l}$ potassium hexacyanoferrate $(1 \% \mathrm{w} / \mathrm{v})$, after stirring the solutions, the tubes are incubated for $20 \mathrm{~min}$ at $50^{\circ} \mathrm{C}$ by addition of $200 \mu \mathrm{l}$ trichloroacetic acid $(10 \% \mathrm{w} / \mathrm{v}), 600 \mu \mathrm{l}$ distilled water, and $120 \mu \mathrm{l}$ ferric chloride $(0.1 \%$, $\mathrm{w} / \mathrm{v}$ ). Absorbance was estimated at $700 \mathrm{~nm}$ against the control using a Perkin Elmer Lambda 40 UV/VIS spectrophotometer. The experiment was performed in triplicates and the average absorption was noted for each concentration. Ascorbic acid was used as a standard. The inhibition percentage calculated according to the formula:

The absorbance of the negative control - The absorbance of the sample The negative control absorbance

The standard graph was plotted as a function of the sample concentration with the ascorbic acid concentration as positive control on the X-axis and the scanning activity in percentage on the coordinate axis.

\section{Statistical analysis}

Data are presented as mean \pm standard deviation of three repetitions. Statistical analysis was performed using the one-factor ANOVA using GraphPad Prism with 95\% confidence limits ( $\mathrm{p}<0.05)$.

\section{RESULTS AND DISCUSSION}

\section{The extraction yields}

The preparation of the extracts from the plant studied was carried out in two stages. The first is extraction by a hydroalcoholic mixture $(7 / 3$, $\mathrm{V} / \mathrm{V}$ ) to obtain initial extract. The yield was determined on the basis of the weight of the dry plant material in powder form and was expressed as a percentage, Fig. 1. The two methods used in this extraction show that methanol is the best solvent with $17.67 \%$, followed by ethanol with a percentage of $15.34 \%$, but the decoction extract $(13.8 \%$ ) remains low compared to the solvents used. The decoction yield is comparable to those obtained on Withania somnifera and lower than those found on $W$. frutescens [11]. In addition, the extraction yield varies according to the species studied, the drying conditions, the secondary metabolite content, the conditions and methods used in extraction, the chemical characteristics, and the nature of the solvents [12].

\section{The ash contents}

The ash rate gives us information on the total amount of mineral salts present in this species, and by deduction, the proportion of organic matter presents in vegetable powder. The results obtained are presented in Table 1, which show that the species studied has an acceptable ash and organic matter content of $23.83 \%$ and $76.16 \%$, respectively.

\section{Mineral elements content}

The results of the ICP-AES analyses carried out at CURI USMBA in Fez are presented in Table 2. These results show significant levels of minerals, including calcium, magnesium, and sodium, in the plant. However, heavy metal levels are very low, particularly for cadmium, nickel, and lead. The use of the aerial part of $W$. frutescens during the flowering period explains the high mineral contents. These results can be interpreted by the richness of pollen grains and leaves in mineral elements. This analysis shows that the species is devoid of certain heavy metals while

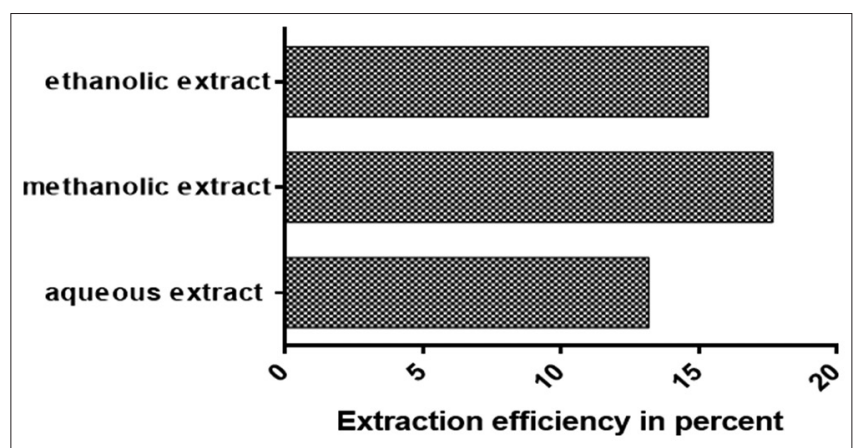

Fig. 1: The extraction yield of hydroalcoholic extracts and aqueous extract

Table 1: The ash and organic matter content of the species studied

\begin{tabular}{lll}
\hline Sample & Ash content (\%) & Organic matter content (MO \%) \\
\hline WIT & $23.83 \pm 0.07$ & $76.16 \pm 0.12$ \\
\hline
\end{tabular}


Table 2: Mineral element analyses by ICP-AES

\begin{tabular}{|c|c|c|c|c|c|c|c|c|c|}
\hline Ca (mg/kg) & Cd (mg/kg) & Co $(\mathrm{mg} / \mathrm{kg})$ & $\mathrm{Cu}$ (mg/kg) & $M g(\mathrm{mg} / \mathrm{kg})$ & Mn (mg/kg) & Mo (mg/kg) & $\mathrm{Na}(\mathrm{mg} / \mathrm{kg})$ & $\mathrm{Ni}$ (mg/kg) & $\mathrm{Pb}(\mathrm{mg} / \mathrm{kg})$ \\
\hline 5330.1 & $<0.001$ & $<0.001$ & 0.23 & 1297.14 & 19.56 & $<0.001$ & 2345.58 & $<0.001$ & $<0.001$ \\
\hline
\end{tabular}

ICP-AES: Inductive coupling plasma-atomic absorption spectroscopy

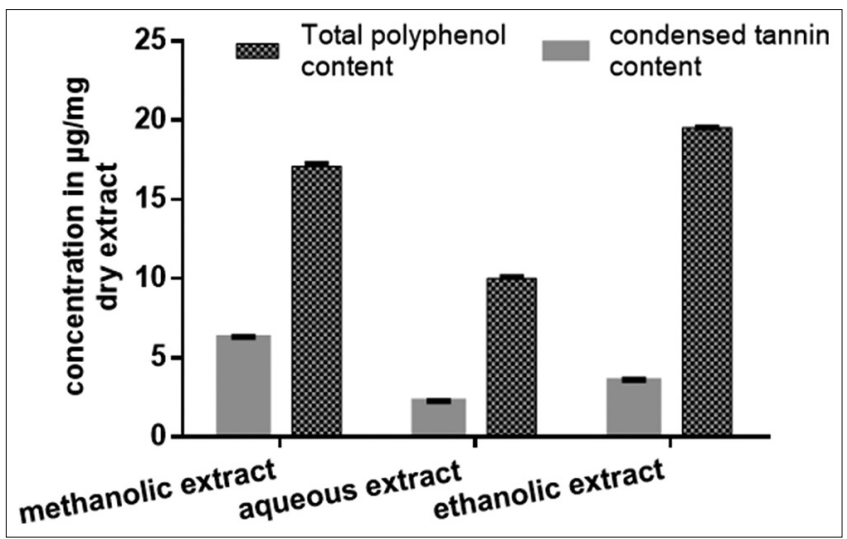

Fig. 2: Phenolic compound extraction yield for the three extracts studied

it has a capacity to adsorb certain heavy metals such as arsenate [13]. $W$. frutescens been selected for the treatment of wastewater, it owns the capacity to adsorb metal elements and anions from wastewater. This plant has no toxic elements and this facilitates its use in pharmacology and can possibly be used to study certain biological tests [3].

\section{Phytochemical screening}

Table 3shows the results of the phytochemical study of aqueous extracts. The study revealed the absence of free quinones (anthracene combined) and polyphenols, especially flavonoids. Furthermore, the test shows the presence of many compounds in the species studied, such as saponins, alkaloids, coumarins, and mucilage. These results are comparable to those found by Chiban [4], he showed that some species of the Solanaceae family are rich in phytochemical compounds such as saponins, coumarins, terpenes, tannins, and alkaloids. The latter compounds are considered among the characteristics of this family, but they represent a toxicity for the plant. Studies have shown that alkaloids have a toxic effect compared to saponins and flavonoids on some pests, and these compounds can be used as natural pesticides [14]. Plants are warehouses of effective phytochemical constituents that are widely used in the pharmaceutical industry, about a quarter of all pharmaceutical products prescribed in developing countries contain compounds that are derived from medicinal plants [15].

\section{Total phenolic and condensed tannin contents}

The quantification of polyphenols was based on a linear calibration curve $Y=11.325 \mathrm{X}+0.0209$ and $\mathrm{r}^{2}=0.9948$ performed by gallic acid at different concentrations under the same sample conditions.

The results are expressed in mg gallic acid equivalent per gram of extract, Fig. 2 . The total polyphenol contents obtained by maceration are the best extraction method on average $19.53 \pm 0.018 \mu \mathrm{g} \mathrm{GAE} / \mathrm{mg}$ ethanolic extract and $17.099 \pm 0.092 \mu \mathrm{g} \mathrm{GAE} / \mathrm{mg}$ methanolic extract compared to $10.015 \pm 0.063 \mu \mathrm{g}$ EAG $/ \mathrm{mg}$ decocted extract. The maceration method is long, expensive, and dangerous for health due to the use of organic solvents [16], but researchers have shown that this extraction by maceration remains the effective method for fragile molecules [17]. The ethanolic solvent gave high levels of total polyphenols $(19.53 \pm 0.018 \mu \mathrm{g}$ GAE/mg MS) followed by methanolic extracts which gave close levels estimated at $17.099 \pm 0.092 \mu \mathrm{g}$ EAG $/ \mathrm{mg}$ extract. The combination of ethanol with water gives a better extraction of total polyphenol [18]

The determination of tannin content in extracts was made according to a linear calibration curve $\left(\mathrm{Y}=0.5943 \mathrm{X}+0.0784\right.$ and $\mathrm{r}^{2}=0.9938$ at
Table 3: Phytochemical screening for $W$. frutescens

\begin{tabular}{ll}
\hline Phytochemical family & Aqueous extract \\
\hline Tannins & - \\
T. catechics & + \\
T. gallic & - \\
Flavonoids & \\
Saponins & ++ \\
Sterols and terpenes & + \\
Steroid heterosides & ++ \\
Triterpene heteroglycoside & ++ \\
Coumarins & \\
Free quinone & - \\
Free anthraquinones & - \\
Combined & - \\
O-heterosis & - \\
Anthracene & - \\
C-heterosis & +++ \\
Clkaloids & + \\
Mucilage & ++ \\
\hline
\end{tabular}

The number of+reflects the intensity of coloring or the importance of the foam for saponins. W. frutescens: Wisteria frutescens

Table 4: DPPH IC50 test in $\mu \mathrm{g} / \mathrm{ml}$

\begin{tabular}{lll}
\hline DPPH IC50 $\mu \mathrm{g} / \mathrm{ml}$ & \\
\hline E-MetOH & E-EtOH & BHT \\
\hline $0.183 \pm 0.004^{* *}$ & $0.056 \pm 0.008^{*}$ & $0.009 \pm 0.0004$ \\
\hline
\end{tabular}

DPPH: 1,2-diphenyl- $\beta$-picrylhydrazyl, $\mathrm{IC}_{50}$ : Half maximal inhibitory

concentration, BHT: Butylated hydroxytoluene

absorbance in $500 \mathrm{~nm}$ ) performed by catechol under the same sample conditions. The results of the tannin content show that aqueous extracts have a high tannin content compared to other hydroalcoholic extracts. Decoction is more effective for extraction of tannins with $6.258 \pm 0.045 \mu \mathrm{g}$ Eqcat/mg MS than maceration 3.535 $\pm 0.062 \mu \mathrm{g}$ Ecat/mg MS. Because it needs a high temperature that facilitates solubility, liberation and extraction of fragile phytochemical compounds [19]. The increase in temperature in extraction by decoction destroys the polyphenol oxidases which decreases the total polyphenol content and an increase in the tannin content, so the chemical nature of the solvents and the operating conditions has an effect on the yield of the tannin content [20].

\section{DPPH radical scavenging activity}

The DPPH method is based on the reduction of methanolic solution of DPPH in the presence of an antioxidant in both extracts of this plant that gives a hydrogen or an electron it causes the non-radical formation of DPPH-H. The antioxidant capacity of the extracts was determined from the half maximal inhibitory concentration $\left(\mathrm{IC}_{50}\right)$; it is the concentration necessary to reduce $50 \%$ of the radical $\mathrm{DPPH}$.

Extensive investigations on the antioxidant activities of phytochemicals have been reported and antioxidant capacity depends on the value of the $\mathrm{IC}_{50}$, the lower the $\mathrm{IC}_{50}$, the higher the antioxidant activity [21]. According to the results presented in Table $4, \mathrm{IC}_{50}$ obtained by BHT $0.009 \pm 0.0004 \mu \mathrm{g} / \mathrm{ml}$, used as a reference molecule, is lower than those of the two extracts and therefore has very high antioxidant activity. By the $\mathrm{IC}_{50}$ value of about $0.056 \pm 0.008 \mu \mathrm{g} / \mathrm{ml}$, ethanolic extract represents a strong antioxidant activity compared to methanolic extract $0.213 \pm 0.004 \mu \mathrm{g} / \mathrm{ml}$. 
Table 5: Reducing power test in $\mu \mathrm{g} / \mathrm{ml}$

\begin{tabular}{lll}
\hline Reducing power $\mathrm{IC}_{50} \boldsymbol{\mu g} / \mathbf{m l}$ & \\
\hline E-MetOH & E-EtOH & Ascorbic acid \\
\hline $0.213 \pm 0.006^{* *}$ & $0.043 \pm 0.004^{*}$ & $0.003 \pm 0.0004$ \\
\hline $\mathrm{IC}_{50}:$ Half maximal inhibitory concentration &
\end{tabular}

The polyphenols contained in our extracts are probably responsible for antioxidant activity. They have an important hydroxyl group, they present a high antioxidant activity [22], and they stabilize free radicals through the atoms they release [23]. Thus, the antiradical capacity has a relation with the number, position, and nature of substituents on the $\mathrm{B}$ and $\mathrm{C}$ rings (hydroxyl, metalaxyl, and glycosylated groups). Hence, the antioxidant effect is not only dose dependent but also structure dependent [24].

\section{The reducing power}

The antioxidant capacity of the plant extracts studied, it was represented in inactivation by reduction of oxidants with a combination of antioxidants present in our extracts studied. According to the results in Table 5, the reducing power of ethanolic extract represents a strong antioxidant activity with an order value of $0.043 \pm 0.004 \mu \mathrm{g} / \mathrm{ml}$ compared to an order value of $0.213 \pm 0.006 \mu \mathrm{g} / \mathrm{ml}$.

This activity remains lower than that of ascorbic acid, but it is a crude extract containing a large number of different phytochemical compounds. It is enough to purify these compounds by a specific extraction for the phenolic contents, which can present a more important activity than that of the total extract. Antioxidant potency is significantly different from one molecule to another and interactions between reactive compounds and antioxidants vary according to biological, chemical, and physical parameters including size, structure, solubility, and oxidoreducing potential [9]. These results, the plant has the antioxidant power to be used, are formed from a drug against certain diseases caused by free radicals [25].

\section{CONCLUSION}

Phytochemical analysis of $W$. frutescens shows that this plant is rich in high quantities of alkaloids, saponins, mucilage, tannins, and coumarins. It contains an average amount of total polyphenols and tannins that confer significant antioxidant activity to the plant studied. However, all these results obtained in vitro are only a first step in the search for biologically active natural substances. Other biological effects in vivo of crude extracts and their active compounds can be evaluated using different techniques. Other studies can be carried out on the molecular scale to determine; on the one hand, the compounds of the plant under study (particularly with regard to the identification and purification of phenolic compounds) that may be responsible for such effects and, on the other hand, the absolute mechanism by which these compounds achieve their antioxidant effects.

\section{ACKNOWLEDGMENTS}

The authors would like to thank the Regional Center of Interface, University Sidi Mohamed Ben Abdallah, Fez, Morocco, for the analyses by ICP-AES.

\section{AUTHORS' CONTRIBUTIONS}

All the authors have contributed equally.

\section{CONFLICTS OF INTEREST}

The authors declare that there are no conflicts of interest regarding the publication of this paper.

\section{REFERENCES}

1. Benmiloud K. Phytochemical Screening, Antioxidant and Anticandidosis Activities of Nepeta Amethystina Extracts. Thesis
Submitted for the Master's Degree in Chemistry. Université Abou BakrBelkaid Tlemcen; 2014.

2. Bellakhdar J. The Traditional Moroccan Pharmacopee, Ancient Arab Medicine and Popular Knowledge. Paris: IBIS Press; 1998.

3. Chiban M, Soudani A, Sinan F, Persin M. Wastewater treatment by batch adsorption method onto micro-particles of dried Withania frutescens plant as a new adsorbent. J Environ Manage 2011; 95:61-5.

4. Chiban M, Amezghal A, Benhima H, Sinan F, Tahrouch S, Seta P. Phytochimical study of some inert plants of south Western Morocco. Rev Biol Biotechnol 2007;6:40-3.

5. Lavoisier Technics and Documents. French Standards NF V 05-113 1972. In: AFNOR, Products Derived from Fruit and Vegetables. $2^{\text {nd }}$ ed. Paris: Lavoisier Technics and Documents; 1986.

6. Judith MD. Etude Phytochimique et Pharmacologique de Cassia Nigricans Vhal (Caeslpiniaceae) Utilis'ee Dans le Traitement des Dermatoses au Tchad, Thèse de Pharmacie; 2005. p. 136-40.

7. Singleton VL, Arossi JA. Coloromitry of total phenolics with phosphomolybdec-phosphotungstic acid reagents. Amer J Enol Vitic $1965 ; 16: 144-53$.

8. Ba K, Tine E, Destain J, Cisse N, Thonart P. Comparative study of phenolic compounds, the antioxidant power of different varieties of Senegalese sorghum and the amylolytic enzymes of their malt. Biotechnol Agro Soc Environ 2010;14:131-9.

9. Brand-Williams W, Cuvelier ME, Berset C. Use of a free radical method to evaluate antioxidant activity. Food Sci Technol 1995;1:25-30.

10. Oyaizu M. Studies on products of browning reactions: Antioxidant activities of products of browning reaction prepared from glucosamin. J Nutrit 1986;44:307-15.

11. Larhsini M, Sebbane R, Kchakech H, Markouk M, Bekkouche K, Abbad A, et al. Screening of certain Moroccan plant extracts for molluscicidal activity. Asian J Exp Biol Sci 2010;1:964-7.

12. Do QD, Angkawijaya AE, Tran-Nguyen PL, Huynh LH, Soetaredjo FE, Ismadji S, et al. Effect of extraction solvent on total phenol content, total flavonoid content and antioxidant activity of Limnophila aromatica. Food Drug Anal 2014;22:296-302.

13. Chiban M, Lehutu G, Sinan F, Carja G. Arsenate removal by withania frutescensplant from the South-Western Morocco. Environ Eng Manage J 2009;8:1377-83.

14. Bouchalta A, Boughdad A, Blenzar A. Biocidal effects of alkaloids, saponins and flavonoids extracted from Capsicum frutescens L.(Solanaceae) on Bemisia tabaci (Gennadius) (Homoptera: Aleyrodidae). Biotechnol Agron Soc Environ 2005;9: 259-69.

15. Sharanappa R, Vidyasagar GM. Plant profile, phytochemistry and pharmacology of Argemone mexicana Linn. A review. Int J Pharm Pharm Sci 2014;6:46-53.

16. Garcia-Salas P, Morales-Soto A, Segura-Carretero A, FernándezGutiérrez A. Phenolic-compound-extraction systems for fruit and vegetable samples. Molecules 2010;15:8813-26.

17. Amor BB. Mastery of the Technological Aptitude of Plant Matter in Active Ingredient Extraction Operations; Controlled Instantaneous Relaxation Texturing DIC, PhD Thesis in Industrial Process Engineering, French; 2008

18. Koffi E, Sea T, Dodehe Y, Soro S. Effect of solvent type on extraction of polyphenols from twenty three ivorianplants. J Anim Plant Sci 2010; 5:550-8.

19. Jokić C, Velić D, Bilić M, Bucić-Kojić A, Planinić M, Tomas S. Modelling of the process of solid-liquid extraction of total polyphenols from soybeans. J Food Sci 2010;28:206-12.

20. Chavan UD, Shahidi F, Naczk M. Extraction ofcondensed tannins from beach pea (Lathyrus maritimus L) as affected by different solvents. J Food Chem 2001;75:509-12.

21. Heim EK, Tagliaferro AR, Bobilya DJ. Flavonoïds antioxydants: Chemistry; Metabolism and structure-activity relationships. J Nutritional Biochem 2002;13:572-84

22. Hebi M, Eddouks M. Evaluation of the antioxidant activity of Stevia rebaudiana. Phytotherapy 2016;14:17-22.

23. De Pinedo AT, Penalver P, Morales JC. Synthesis and evaluation of new phenolic-based antioxidants: Structure-activity relationship. Food Chem 2007;103:55-61.

24. Rodriguez-Bernaldo AQ, Frecha P, Vidal A, Lopez HJ. Antioxydan compounds in edible brown seweeds. Eur Food Res Technol 2010;231:495-8.

25. Sharma RA, Yadav A, Bharadwaj R. DPPH free radical scavenging activity of phenolic compounds in Argemone mexicana. Int J Pharm Pharm Sci 2013;5:683-6. 